\title{
A Lei 10.639/2003 e a Escola de Educação Especial: um desafio a mais para a formação de professores
}

\section{The Law 10.639/2003 and the School of Special Education: a challenge more training of teachers}

\author{
Elânia de Oliveira ${ }^{1}$
}

\begin{abstract}
RESUMO
O artigo apresenta elementos para uma reflexão sobre a implementação do artigo 26-A da LDB (modificado pelas Leis 10.639/2003 e 11.645/2008) à luz dos desafios da educação especial. $\mathrm{O}$ artigo analisa as práticas pedagógicas no contexto de uma escola especializada em educação de surdos. Dados coletados em uma escola da Região Sudeste do país, na pesquisa nacional "Práticas pedagógicas de trabalho com relações étnico-raciais na escola na perspectiva de Lei 10.639/2003", em instituição de ensino especializada no atendimento a estudantes surdos, sugerem que, para além da formação específica dos profissionais, a Educação das Relações Étnico-Raciais é também uma demanda urgente.
\end{abstract}

Palavras-chave: práticas pedagógicas; Educação Especial; Lei 10.639/2003.

\begin{abstract}
The paper presents elements for a reflection on the implementation of Article 26-A of the LDB (modified by Law 10.639/2003 and 11.645/2008) in the light of the challenges of special education. The article examines the pedagogical practices in the context of a school specializing in deaf education. Data collected in a school in the Southeast, the national research "Pedagogical
\end{abstract}

${ }^{1}$ Doutora em Educação. Docente da Universidade Federal de Minas Gerais. Integrante do Núcleo de Estudos sobre Relações Raciais e Ações Afirmativas (NERA), Brasil. E-mail: elaniadeoliveira.oliveira@gmail.com 
practices with ethnic-racial relations in the school from the perspective of Law 10.639/2003", in an educational institution specialized in caring for deaf students, suggest that in addition to specific training for professionals, education for the ethnic-racial relations is also an urgent demand.

Keywords: pedagogical practices; Special Education; Law 10.639/2003.

\section{Introdução}

A aplicação da Lei 10.639/2003 e das Diretrizes Curriculares Nacionais para a Educação das Relações Étnico-Raciais e para o Ensino de História e Cultura Afro-Brasileira e Africana apresenta para as escolas desafios que demandam de todos os profissionais envolvidos no trato com os estudantes uma postura atenta e crítica para as atividades escolares que costumeiramente são realizadas nas escolas. Trata-se de um exercício de desnaturalizar o olhar sobre as práticas pedagógicas, buscando certo estranhamento para aquilo que é realizado rotineiramente (GREEN; WALLAT, 1981; MOITA LOPES, 2002; CASTANHEIRA, 2004; CASTANHEIRA et al. 2007; BLOOME et al., 2005).

Exercitar o olhar sobre as práticas cotidianas, numa perspectiva de combate ao racismo, como está proposto na Lei 10.639/2003 e nas Diretrizes Nacionais que a ela estão vinculadas, é ter em conta que os processos envolvidos na construção identitária dos sujeitos estão permeados por conflitos e tensões que atingem diretamente alunos e professores. São relações que opõem pessoas tentando se afirmar umas diante das outras num espaço marcado por discursos hegemônicos, como é a escola. Nesse embate, os modos de construção do "eu" estão entrelaçados ao modo como o "outro" enxerga esse eu. O problema é que nem sempre essa imagem social que é feita de mim corresponde à imagem que eu construí de mim mesmo, o que gera um conflito que é coletivo, ainda que muitas vezes pareça individual (GOMES, 2006). Dessa forma, considerar a diversidade nas práticas pedagógicas é ter em conta, também, que as identidades e as diferenças implicam processos de aproximação e distanciamentos, em um jogo complexo por meio do qual aprendemos, aos poucos, sobre os contornos da nossa identidade, estabelecidos pelas diferenças e pelo trato social, cultural, histórico e político (GOMES, 2007, p. 98).

Compreender o cotidiano das práticas escolares, seja dentro da sala de aula ou em outros espaços da escola, tais como bibliotecas, auditórios, pátios etc., significa, pois, considerar que a construção e a reconstrução de certos processos socialmente determinados, como o processo identitário, por exemplo, 
são passíveis de serem observados quando atentamos para as regularidades e os padrões vivenciados nesses espaços (KLEIMAN, 1998).

\section{Contexto da escola}

A Escola Cinco,${ }^{2}$ uma das seis escolas selecionadas na Região Sudeste, é uma instituição escolar de apoio a alunos surdos e que, conforme observado no campo e nos relatos dos profissionais, exerce um papel fundamental na formação daqueles que são atendidos lá. A escola atende regularmente em torno de 60 alunos, com idade entre 5 e 25 anos, embora esse número varie, uma vez que o atendimento é realizado em dias específicos para cada grupo de estudantes e a frequência depende de diversos fatores, entre eles a disponibilidade dos responsáveis para acompanhá-los, o estado de saúde deles etc. São atendidos estudantes surdos, surdos com forte resíduo auditivo (escutam um pouco) e surdos com múltiplas deficiências, incluindo vários com problemas de locomoção e cadeirantes.

Não há dados oficiais na escola sobre o perfil étnico-racial e de gênero dos estudantes. Observa-se uma ligeira predominância de brancos, mas é forte a presença de estudantes negros/as, principalmente entre o grupo de adolescentes. Quanto ao gênero, parece haver um equilíbrio entre o número de mulheres e homens atendidos.

De acordo com os profissionais, para alguns jovens que não frequentam mais uma escola regular, a Escola Cinco acaba se constituindo, muitas vezes, no único espaço que eles têm para se socializarem com seus pares, uma vez que nem sempre as famílias têm condições de oferecer o atendimento necessário àquele jovem ou criança, em função de diversos fatores, entre eles a dificuldade de aceitação da deficiência (ou deficiências) dos filhos e filhas ou por não saberem a língua de sinais. Esse quadro poderia ser revertido, afirmam eles, se os familiares aprendessem Libras, por exemplo. No entanto, não é o que ocorre. Mesmo a escola oferecendo cursos para os familiares, em geral a adesão é muito baixa e os que iniciam o curso desistem bem no início, afirmam os entrevistados.

Nesse sentido, conforme será possível observar a partir de alguns trechos de entrevistas com profissionais e estudantes, a questão racial, seus dilemas e desafios, como acontece em todos os espaços, estão muito presentes no cotidiano

${ }^{2}$ Neste artigo, a escola será designada como Escola Cinco e todas as pessoas citadas no texto tiveram seus nomes alterados. 
de uma escola que atende a alunos surdos, como é o caso da Escola Cinco. Essa escola se insere, portanto, nesse contexto de uma escola que tem por desafio reverter uma concepção ultrapassada de trabalho com os surdos que consistia, em outros tempos, em usar métodos, muitos deles agressivos, ${ }^{3}$ para que eles adquirissem alguma oralidade e tentassem se expressar como ouvintes e, ao mesmo tempo, reconhecer a diversidade étnico-racial dos seus alunos e alunas e desenvolver práticas na perspectiva da Lei 10.639/2003.

Vale destacar que muitos alunos que frequentam a escola não são alfabetizados nem em Libras nem em Português. Na Escola Cinco, eles recebem incialmente aulas de Libras, o que garante a possibilidade de se comunicarem com outras pessoas que também já sabem a língua de sinais, para depois aprenderem o Português que, como sabemos, demanda tempo e esforço, principalmente dos adolescentes e dos adultos. Portanto, muitos desafios são colocados para uma escola como essa na aplicação de duas leis que exigem muita formação. A exigência do ensino de Libras (Língua Brasileira de Sinais) ocorre em atendimento ao Decreto 5.626, de 22/12/2005, que regulamenta a Lei 10.436, de 24/04/2002.

\section{A escola e as práticas na perspectiva da Lei 10.639/2003}

$\mathrm{Na}$ Escola Cinco, assim como ocorre em outras escolas, o reconhecimento da importância de um trabalho na perspectiva da Lei 10.639/2003 não é uma unanimidade entre os profissionais. No caso dessa escola, em particular, alguns tendem a acreditar que, por se tratar de uma escola inclusiva, a questão da diversidade, da inclusão dos indivíduos já está posta, não sendo necessário um trabalho específico na perspectiva da diversidade étnico-racial. Mesmo assim, o que se viu na escola foi que a maioria dos profissionais envolvidos com os estudantes surdos, incluindo funcionários da cozinha e serviços gerais, se mostrou entusiasmada com a participação na pesquisa e preocupada em envolver os estudantes

\footnotetext{
${ }^{3} \mathrm{Na}$ escola ainda se observam algumas carteiras com partes de aparelhagem usadas tempos passados para que os/as alunos/as surdos/as colocassem o rosto e ficassem tentando articular sons. De acordo com os professores, são aparelhos que trazem tristes lembranças de tempos que todos desejam esquecer. O horror a esses métodos também foi expresso por um ex-aluno, hoje com 33 anos, que esteve visitando a escola durante a coleta de dados. Aliás, vários ex-alunos vão frequentemente lá, exercitam Libras, reveem os professores, conversam com os alunos mais jovens, como foi possível observar.
} 
e seus familiares nos projetos, o que mostra que um pouco mais de incentivo e de formação pode fazer a diferença nesse processo de implementação da Lei.

As práticas observadas na Escola Cinco, no período de 05 a 09 de outubro de 2009, mostram um conjunto de atividades em torno de uma proposta de projeto, elaborado com a colaboração das duas pedagogas da escola, para ser desenvolvido ao longo do segundo semestre de 2009, atendendo assim a proposta da Secretaria de Estado da Educação para todas as escolas. Várias dessas atividades foram estruturadas de forma interdisciplinar e por isso, segundo as professoras, estava sendo interessante. A culminância desse projeto estava prevista para a semana de 20 de novembro 4 daquele ano. De acordo com a diretora, naquele ano fazia parte da proposta realizar um evento na praça, envolvendo as famílias e a comunidade.

A seguir, serão apresentadas três atividades desenvolvidas na Escola Cinco, extraídas do corpus da pesquisa. Elas foram selecionadas porque possibilitam verificar o esforço dos profissionais de realizarem práticas voltadas para a implementação da Lei, mas também permitem verificar que se trata de um conjunto de práticas de iniciativa individual, envolvendo alguns docentes e não o coletivo, e que a proposição das Diretrizes ainda não está inserida no Projeto Político-Pedagógico da escola. A seleção das atividades levou em conta que, nas análises do discurso das práticas desenvolvidas na sala de aula ou fora dela, o ensino da língua, seja a Língua Portuguesa ou Libras, associado a uma preocupação com o processo identitário dos envolvidos, é uma questão que envolve o discurso como um processo de construção social.

Dessa forma, entende-se que a linguagem deve ser pensada em função do uso dela nesse espaço, linguagem que é empregada para fazer alguma coisa e significar alguma coisa. Linguagem produzida e interpretada em um contexto de um mundo real, isto é, construído discursivamente por meio dos recursos que a pessoa tem disponíveis para se comunicar (CAMERON, 2001). Portanto, ao analisar o discurso das práticas aqui selecionadas, a atenção se volta não só para aquilo que os estudantes e os profissionais dizem, mas também para o modo como as coisas foram ditas. Esse processo de análise nos dá a possibilidade de compreender um pouco melhor a forma como as pessoas aprendem as coisas, como elas se apropriam do discurso (CAMERON, 2001). No caso em questão, ele pode nos auxiliar a entender como os estudantes surdos parecem ter se apropriado ou não das propostas de trabalho desenvolvidas pelos profissionais.

\footnotetext{
${ }^{4}$ Data em que se comemora o Dia Nacional da Consciência Negra.
} 


\section{Atividade 1 - 06/10/2009}

A atividade 1 refere-se a uma proposta de trabalho da professora Camila com uma turma de alunos adolescentes e adultos em processo de alfabetização em Português e que já sabiam se comunicar relativamente bem em Libras. O objetivo do trabalho era realizar a leitura e a interpretação da história do livro Menina bonita do laço de fita (MACHADO, 2000). A professora aproveita esse momento para ensinar aos estudantes a diferença entre os termos preto (cor) e preto/negro (pertencimento étnico-racial) que, segundo ela, estava sendo empregado indistintamente pelos estudantes e é importante que eles saibam utilizá-los adequadamente nas situações de comunicação.

Nessa atividade, a professora contou com a participação da intérprete Júlia, estudante de pedagogia, na faixa dos 28 anos, negra, com especialização em Libras e que trabalhava há cerca de três anos na Escola Cinco. Com a ajuda de Júlia, conforme trecho a seguir, foi possível compreender o que estava ocorrendo nesse processo de ensino e aprendizagem dos alunos:

Porque nos sinais tem diferenças pra certos sinais que vocêfaz. Então às vezes eles não entendem muito bem. Eles também estão num processo de aprendizado na vida também. Então o que acontece quando eles vão se referir a preto, eles se referem às vezes como raça pra objeto. Então eu quis colocar pra eles a diferença porque eles já haviam aprendido antes sobre os sinais. E cores. E nós explicamos que cores para objetos era diferente de cores para as raças. Então pra ficar bem frisado ali na... no texto que raça é diferente, né, de objeto. Nós estamos falando de raça, então eu falei com eles que raça, cor negra, era um sinal. Agora cor preta para objeto era outro sinal, que não pode confundir. Ai eu dei exemplo né. Por exemplo, eu mesma, eu sou negra. Então meu sinal... sinal de negro é esse sinal, porque pertence ao sinal do mapa do país África. Esse é o sinal do país África. Então aí tem pra eles saberem. Porque quando eles virem o sinal de novo eles vão ligar. Ah, o país África, pessoa negra. E a diferença de cor. Qualquer objeto é outro sinal (JÚLIA).

\section{Atividade 2 - 07/10/2009}

Outra prática observada foi na aula de alunos com múltiplas deficiências, da professora Angélica. Muito entusiasmada, ela decidiu também trabalhar a 
história Menina bonita do laço de fita (MACHADO, 2000). Para isso, ela teve de pedir emprestado o livro de outra escola e trouxe para a sala bonecas, uma negra e uma branca. Ela conta que, como parte das atividades, os alunos deveriam recortar fotos de pessoas diferentes, brancas, negras etc. Seu espanto foi grande quando observou que os alunos não estavam recortando fotos de pessoas negras. Ao serem indagados, eles disseram que eram feias, não iriam recortar. Um dos alunos se recusou terminantemente a fazê-lo. Ela aproveitou essa situação para discutir com eles as diferenças, mostrar pessoas negras de renome, bonitas e importantes. O resultado foi um cartaz que foi colado na porta da sala de aula com fotos de artistas e personalidades famosas, todas negras. Vale destacar que o aluno que se recusou a recortar pessoas negras para colar no cartaz foi visto participando muito entusiasmado, em outra sala, no dia seguinte, do ensaio da peça de teatro sobre "Aceitação das diferenças", com a intérprete Júlia, como será relatado mais adiante. A peça seria encenada para todos da escola e familiares.

A atitude do estudante parece ser um indicador de que ele não compreendeu que o discurso da igualdade, do respeito às diferenças, como seria trabalhado no texto do teatro e como pretendiam as professoras, deveria valer também para o respeito à diversidade étnico-racial. Sua atitude reforça o que podemos chamar de aspecto conservador do senso comum, que se manifesta na aceitação de certos processos sociais, exatamente como se apresentam, como parecem ser, no sentido que propõe Geertz (1978). No caso em questão, o estudante manifesta-se dentro desse senso comum, repetindo e reforçando o estereótipo sobre a figura do negro como sendo feio. Trata-se de uma questão que merece ser considerada quando se trata de pensar sobre o modo como os estudantes interagem com os discursos que circulam nas atividades propostas na escola (BAKHTIN, 1992; OLIVEIRA, 2008).

\section{Atividade 3 - 08/10/2009}

A atividade 3 trata da encenação de uma peça de teatro, como parte de um conjunto de outras atividades elaboradas pela professora Cecília, cujo objetivo era discutir com os estudantes a questão das diferenças, a importância de aceitá-las, de respeitar o outro etc. A intérprete Júlia, juntamente com a instrutora de Libras da turma da manhã e a instrutora da tarde, foram as responsáveis pela elaboração do texto e do ensaio com os estudantes da manhã e da tarde. $\mathrm{Na}$ plateia, estavam diversos familiares e estudantes/estagiários da escola. À tarde, a participação foi maior e contou com maior número de ouvintes. 
Júlia conta de onde veio o estímulo para o teatro sobre preconceiro e o modo como motivou os estudantes a participarem:

Eu estava querendo fazer um teatro relacionado à etnia, mas eu queria saber assim onde começar. Então eu passei a observar os alunos. Então, observando e vendo o modo que eles têm com eles mesmos. $O$ preconceito, igual aos alunos que são negros. Então eu pensei: eu vou fazer um teatro relacionado com o preconceito. Porque isso faz parte da vida deles. Eles também têm muito preconceito. Então eu tenho que usar alguma coisa que vai mexer com eles e pode atingir a eles de uma forma que pode provocar mudanças. [...] Então eu pensei em alguns alunos. [...] Os que tinham preconceito racial e os alunos que têm preconceito de surdo contra outro deficiente. [...] E fui treinando com eles. Ensaiei a fase inicial, o que eles iam fazer e quando chegar a hora de eles contarem a vida deles, eles mesmos vão se expressar e perguntar a sua opinião. Você tem algum problema? Alguma pessoa te despreza? Você tem algum preconceito? Como que você encara? Ai ele fala sobre o problema que ele tem. Como é. Se ele tem preconceito ou não. Ai eu deixei que eles mesmos se expressassem. E o interessante foi que todos os alunos queriam participar do teatro (JÚLIA).

Indagada sobre a continuidade do trabalho que estavam realizando naquele semestre e o que é necessário para que negros e brancos convivam melhor na escola e na sociedade, Júlia destaca a importância da sua continuidade, principalmente considerando a especificidade do trabalho com os alunos/as surdos/ as e o que ela observa de mudança no comportamento deles com atividades dessa natureza:

Muito importante, né, porque a gente tem que dar continuidade porque isso ajuda bastante. Traz esclarecimento pra eles. Precisa. E pra nós também, né? Pra todos nós. [...] Olha o trabalho aqui como é com crianças surdas, tem que ter pra eles a questão visual, então eu acho importante a gente continuar trabalhando, fazendo o que nós já começamos a fazer através do teatro, através de grupos. Fazerem algumas atividades, né, práticas mesmo, relacionadas com isso. Como, por exemplo, a professora usou a atividade lá relacionada com o futebol. Então isso ajuda bastante eles. Os próprios alunos criaram o... fizeram um mosaico relacionado com cores. Outra professora fez os bonecos. Trouxe os bonecos mostrando as diferenças. Então são questões que 
eles estão vivenciando. Estão vendo. Então se a gente dá continuidade a isso vai ajudar bastante porque isso não vai sair da mente. Porque como eu já tinha falado antes, eles só têm essa visão com a gente porque é Libras. É o modo dele se expressar. É a língua materna deles. Então eles vão ter uma compreensão boa com isso. Então, de repente se fosse uma escola regular eles entenderiam até certo ponto. Mas não tudo porque é um ouvinte falando, às vezes sem intérprete. Porque às vezes não tem. Mas quando é tudo direcionado a Libras, então a gente aproveita toda a gramática de Libras. [...] Dá atenção a eles. Deixar que eles se expressem, que falem a opinião deles. Então isso também é explorado. Então, continuando ajuda bastante. Por exemplo, nós trouxemos aqui pra assistir com eles um filme de uma surda que é cega. Então depois que terminou ofilme eu e a instrutora fizemos o seguinte: vamos ver agora... Você viu a cega? Ela é surda. Ela é cega. Ela não aprendia nada, mas a família não desistiu. E o próprio profissional que estava trabalhando com ela também não desistiu. Então no fim o resultado foi o quê? Ela conseguiu aprender Libras (JÚLIA).

O depoimento de Júlia reforça o entusiasmo que observamos nos professores da escola e, ao mesmo tempo, destaca a importância da formação para que esses profissionais encontrem outras possibilidades de atuação junto aos alunos no enfrentamento dos problemas que surgem no cotidiano relacionados aos estereótipos, ao preconceito racial, entre outros.

\section{Considerações finais}

Os depoimentos e as atividades desenvolvidas na Escola Cinco mostram que o trabalho de implementação da Lei 10.639/2003 se encontra em processo inicial. Foi possível observar nas atividades desenvolvidas que, mesmo com dificuldades de expressão, os alunos mostraram que compreenderam o objetivo das atividades, como ocorreu com a proposta do teatro. No entanto, é preciso avançar nesse processo para que os estudantes possam aprender outros elementos quando se pensa na identidade étnico-racial, como é o caso de aprender sobre África, sua história, desconstruir estereótipos sobre a população negra etc. Essa questão, que já é cercada de tensões na escola regular, pois demanda conhecimento e construção de estratégias de trabalho com os estudantes, mostra-se muito mais tensa ainda quando voltada para estudantes que estão aprendendo a se comunicar em Libras. 
O entusiasmo dos profissionais e o envolvimento dos alunos sugerem, no entanto, que os trabalhos na perspectiva da Lei encontram terreno fértil na escola de educação especial para sua construção. Fica evidente, também, nas práticas, a necessidade de inclusão dos professores da educação especial nos cursos de formação na perspectiva da Lei 10.639/2003 e suas Diretrizes, de forma que essas práticas percam o caráter temporário, de projetos esporádicos, algumas vezes pouco contextualizados, e façam parte do currículo escolar, integrando o Projeto Político-Pedagógico da Escola.

\section{REFERÊNCIAS}

BAKHTIN, Mikhail Volochinov. Marxismo e filosofia da linguagem. Tradução de Michel Lahud e Yara Frateschi Vieira. São Paulo: HUCITEC, 1992.

BLOOME, David; CARTER, Stephanie; CHISTIAN, Beth; OTTO, Sheilla; SHUARTFARIS, Nora. Discourse analysis and the study of classroom language and literacy events: a microethnographic perspective. New Jersey: Lawrence Erlbaum Associates, Publishers, 2005.

BRASIL. Presidência da República. Lei 10.436, de 24 de abril de 2002. Dispõe sobre a Língua Brasileira de Sinais - Libras e dá outras providências. Disponível em: $<$ http:// www.planalto.gov.br/ccivil_03/leis/2002/L10436.htm>. Acesso em: 20/08/2012.

. Presidência da República. Lei 10.639 de 9 de janeiro de 2003. Altera a Lei 9.394, de 20 de dezembro de 1996, que estabelece as diretrizes e bases da educação nacional, para incluir no currículo oficial da Rede de Ensino a obrigatoriedade da temática "História e Cultura Afro-Brasileira", e dá outras providências. Disponível em: $<$ http://www. planalto.gov.br/ccivil_03/leis/2003/L10.639.htm>. Acesso em: 20/08/2012.

. Decreto 5.626, de 22 de dezembro de 2005. Regulamenta a Lei $\mathrm{n}^{\circ} 10.436$, de 24 de abril de 2002, que dispõe sobre a Língua Brasileira de Sinais - Libras, e o art. 18 da Lei $\mathrm{n}^{\circ}$ 10.098, de 19 de dezembro de 2000. Disponível em: <http://www.planalto. gov.br/ccivil_03/_ato2004-2006/2005/decreto/d5626.htm>. Acesso em: 20/08/2012.

CAMERON, Deborah. Working with spoken discourse. London: Sage Publications, 2001.

CASTANHEIRA, Maria Lúcia. Aprendizagem contextualizada: discurso e inclusão na sala de aula. Belo Horizonte: Ceale; Autêntica, 2004.

; GREEN, Judith; DIXON, Carol N. Práticas de letramento em sala de aula: uma análise de ações letradas como construção social. Revista Portuguesa de Educação, v. 20, n. 2, p. 7-38, 2007. 
GEERTZ, Clifford. A interpretação das culturas. Rio de Janeiro: Zahar, 1978.

GOMES, Nilma Lino. Sem perder a raiz: corpo e cabelo como símbolos da identidade negra. São Paulo: Autêntica, 2006.

. Diversidade étnico-racial e educação no contexto brasileiro: algumas reflexões. In: _. (Org.). Um olhar além das fronteiras: educação e relações raciais. Belo Horizonte: Autêntica, 2007. p. 97-110.

GREEN, Judith; WALLAT, Cinthia (Ed.). Ethnography and language in educational settings. Norwood, NJ: Ablex, 1981. p. 65-83.

KLEIMAN, Ângela. A construção de identidade em sala de aula: um enfoque interacional. In: SIGNORINI, Inês (Org.). Lingua(gem) e identidade: elementos para uma discussão no campo aplicado. Campinas: Mercado de Letras, 1998.

MACHADO, Ana Maria. Menina bonita do laço de fita. São Paulo: Ática, 2000.

MEHAN, Hugh. Learning lessons: social organization in the classroom. Cambridge: Harvard University Press, 1979.

MOITA LOPES, Luiz Paulo da. Identidades fragmentadas: a construção discursiva de raça, gênero e sexualidade em sala de aula. Campinas: Mercado de Letras, 2002.

OLIVEIRA, Elânia de. Relações raciais e de gênero e o discurso da sala de aula de português: uma abordagem etnográfica interacional. Tese (Doutorado em Educação) Universidade Federal de Minas Gerais. Belo Horizonte, 2008.

Texto recebido em 05 de abril de 2012.

Texto aprovado em 22 de julho de 2012 . 